\title{
Development and Validation for Simultaneous Estimation of Proguanil and Atovaquone by using RP-HPLC
}

\author{
A Lakshmana Rao ${ }^{* 1}$, T Prasanthi ${ }^{1}$, Fazeela Thunnisa ${ }^{1}$
}

Department of Pharmaceutical Analysis, V V Institute of Pharmaceutical Sciences, Gudlavalleru, AP, India.

Received: 20 November, 2017; Accepted: 29 November, 2017; Published: 12 April, 2018

*Corresponding author: A Lakshmana Rao, Professor \& Principal, V V Institute of Pharmaceutical Sciences, Gudlavalleru, A.P, India, E-mail: dralrao@ gmail.com

\begin{abstract}
A simple, precise and rapid RP-HPLC method has been developed for the simultaneous determination of Proguanil and Atovaquone in pharmaceutical dosage form. The method was carried out using Kromasil C18 column (150 mm x $4.6 \mathrm{~mm}, 5 \mu \mathrm{m})$ and mobile phase comprised of $0.1 \%$ Ortho Phosphoric Acid(OPA):Acetonitrile(ACN) in the ratio of $50: 50 \mathrm{v} / \mathrm{v}$ and degassed under ultrasonication. The flow rate was $1.0 \mathrm{~mL} / \mathrm{min}$ and the effluent was monitored at 287 $\mathrm{nm}$. The retention times of Proguanil and Atovaquone were 2.15 min and 2.48 min respectively. The method was validated in terms of linearity, precision, accuracy, and specificity, limit of detection and limit of Quantitation. Linearity was in the range of 25 to $150 \mu \mathrm{g} / \mathrm{mL}$ for Proguanil and 62.5 to $375 \mu \mathrm{g} / \mathrm{mL}$ for Atovaquone respectively. The percentage recoveries of both the drugs were ranging from 98.86 to 99.97\% for Proguanil and 99.52 to $99.79 \%$ for Atovaquone respectively from the tablet formulation. The proposed method is suitable for the routine quality control analysis of simultaneous determination of Proguanil and Atovaquone in bulk and pharmaceutical dosage form.
\end{abstract}

Keywords: Proguanil; Atovaquone; RP-HPLC; Validation

\section{Introduction}

Proguanil (Figure 1) is a biguanide derivative and exerts its antimalarial action by inhibiting parasitic dihydrofolate reductase enzyme. Proguanil is chemically (1E)-1-[amino-(4-chloroanilino) methylidene]-2-propan-2-yl guanidine. It is converted to an active metabolite called cycloguanil and it has causal prophylactic and suppressive activity against $P$. falciparum and cures the acute infection. It is also effective in suppressing the clinical attacks of vivax malaria. Proguanil inhibits the dihydrofolate reductase of plasmodia and thereby blocks the biosynthesis of purines and pyrimidines, which are essential for DNA synthesis and cell multiplication [1]. This leads to failure of nuclear division at the time of schizont formation in erythrocytes and liver.

Atovaquone (Figure 2) is a highly lipophilic drug that closely resembles the structure ubiquinone. Atovaquone is chemically 2-(trans-4-(p-chlorophenyl) cyclohexyl)-3-hydroxy-1,4 naphthoquinone. Atovaquone is a hydroxy-1,4-naphthoquinone, an analog of ubiquinone, with antipneumocystis activity.
Its inhibitory effect being comparable to ubiquinone, in sensitive parasites Atovaquone can act by selectively affecting mitochondrial electron transport and parallel processes such as ATP and pyrimidine biosynthesis in Plasmodia Atovaquone has the advantage of not causing myelosuppression, which is an important issue in patients who have undergone bone marrow transplantation [2].

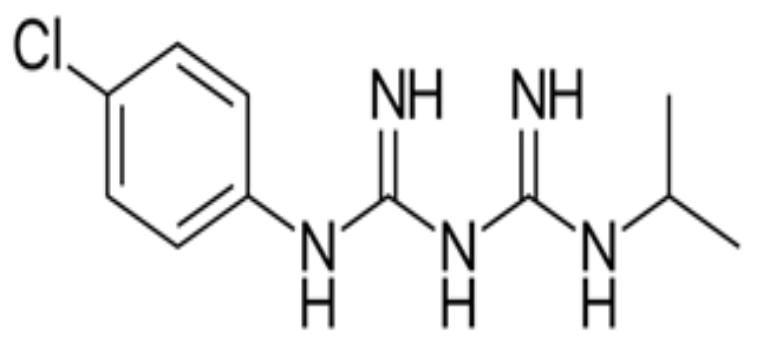

Figure 1: Structure of Proguanil

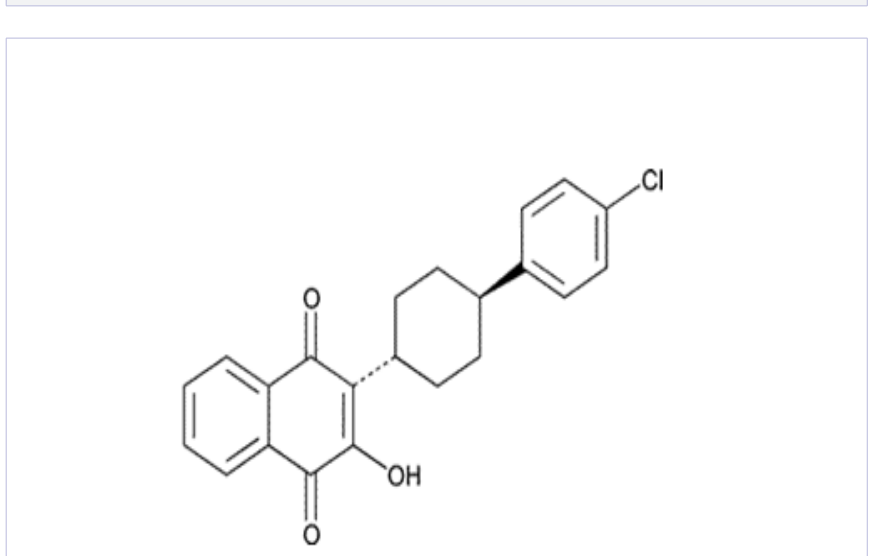

Figure 2: Structure of Atovaquone

Literature survey reveals that several analytical methods have been reported for Proguanil and Atovaquone individually in biological fluids and in pharmaceutical dosage forms [3-8]. Few analytical methods using Spectrophotometry [9], HPLC [10- 
12] and LC-MS [13] have been reported for the simultaneous determination of Proguanil hydrochloride and Atovaquone in combined dosage forms. The objective of the present study was to develop and validate a simple, accurate and precise HPLC method for simultaneous determination of Proguanil and Atovaquone.

\section{Experimental Instrumentation}

HPLC instrument used was of WATERS HPLC 2695 SYSTEM with Auto Injector and PDA Detector. Software used is Empower 2. UV-VIS spectrophotometer PG Instruments T60 with special bandwidth of $2 \mathrm{~mm}$ and $10 \mathrm{~mm}$ and matched quartz was be used for measuring absorbance for Proguanil and Atovaquone solutions. Degassing of the mobile phase was done by using an ultrasonic bath sonicator. A Shimadzu balance was used for weighing the materials.

\section{Chemicals and Solvents}

The reference samples of Proguanil hydrochloride (API) and Atovaquone (API) were obtained from Spectrum Labs, Hyderabad, India. The branded formulations (tablets) (MALARONE tablets containing $10 \mathrm{mg}$ of Proguanil and $25 \mathrm{mg}$ of Atovaquone) were procured from the local market. HPLC grade acetonitrile and analytical grade OPA was obtained from Rankem Chemicals Ltd, Mumbai, India. Hydrochloric acid, sodium hydroxide, hydrogen peroxide of analytical grade was obtained from Merck Chemicals Ltd, Mumbai, India. Milli- $Q$ water was used throughout the experiment.

Diluent: The mixture of water and acetonitrile in the ratio of 50:50 v/v was prepared and used as diluent (blank).

\section{Chromatographic conditions}

HPLC was connected with Kromasil C18 column (150 mm x $4.6 \mathrm{~mm}, 5 \mu \mathrm{m}$ ) as stationery phase. A mixture of 0.1\%OPA and acetonitrile in the ratio of 50:50 v/v was prepared and used as mobile phase. $0.1 \% \mathrm{OPA}$ was prepared by transferring $1 \mathrm{~mL}$ of OPA solution in a $1000 \mathrm{~mL}$ of volumetric flask adds about 100 $\mathrm{mL}$ of milli- $\mathrm{Q}$ water and final volume make up to $1000 \mathrm{~mL}$ with milli-Q water. Injection volume was $10 \mu \mathrm{L}$ and flow rate was 1.0 $\mathrm{mL} / \mathrm{min}$ and run time was $5.0 \mathrm{~min}$. The column was maintained at ambient temperature and the eluent was monitored at $287 \mathrm{~nm}$.

\section{Preparation of standard solution}

Accurately Weighed and transferred $10 \mathrm{mg}$ of Proguanil and $25 \mathrm{mg}$ of Atovaquone working standards into a $10 \mathrm{~mL}$ clean dry volumetric flask, add $3 / 4^{\text {th }}$ volume of diluent, sonicated for 5 minutes and make up to the final volume with diluents. $1 \mathrm{~mL}$ from the above two stock solutions was taken into a $10 \mathrm{~mL}$ volumetric flask and made up to $10 \mathrm{~mL}$. Standard stock solution was diluted to get a concentration of $25-150 \mu \mathrm{g} / \mathrm{mL}$ and $62.5-375 \mu \mathrm{g} / \mathrm{mL}$ for Proguanil and Atovaquone respectively.

\section{Preparation of sample solution}

Twenty tablets were weighed and finely powdered. An accurately weighed portion of powder sample equivalent to 10 $\mathrm{mg}$ of Proguanil and $25 \mathrm{mg}$ of Atovaquone was transferred to a 10 $\mathrm{mL}$ volumetric flask containing diluent. The contents of the flask were sonicated for about 30 min for complete solubility of the drug and volume made up with further quantity of diluent. Then this mixture was filtered through $0.45 \mu$ membrane filter. $1 \mathrm{~mL}$ of this filtrate was further diluted to $10 \mathrm{~mL}$ with diluent.

\section{Method development}

Preliminary development trials have performed with octyl and octadecyl columns with different types, configurations and from different manufacturers. Finally the expected separation and shapes of peak was succeeded in Kromasil C18 column. To effect ideal separation of the drug under isocratic conditions, mixtures of solvents like water, methanol and acetonitrile with or without different buffers in different combinations were tested as mobile phases on a C18 stationary phase. A mixture of $0.1 \% \mathrm{OPA}$ and acetonitrile in proportion of ratio $50: 50 \%$ $\mathrm{v} / \mathrm{v}$ was proved to be the most suitable of all the combinations since the chromatographic peaks obtained were better defined and resolved and almost free from tailing. The spectra of the both Proguanil and Atovaquone were showed that a balanced wavelength was found to be $287 \mathrm{~nm}$. Flow rates of the mobile phase were changed from $0.5-1.0 \mathrm{~mL} / \mathrm{min}$ for optimum separation. It was found from the experiments that $1.0 \mathrm{~mL} / \mathrm{min}$ flow rate was ideal for the successful elution of the analyte. The above optimized chromatographic conditions were followed for the simultaneous determination of Proguanil and Atovaquone in bulk samples and its combined tablet formulations.

\section{Validation of the proposed method}

The proposed method was validated as per ICH $[14,15]$ guidelines. The parameters studied for validation were specificity, linearity, system suitability, precision, accuracy, robustness, limit of detection, limit of quantification, and solution stability.

\section{Specificity}

A study conducted to establish specificity of the proposed method involved injecting standard, sample, blank and placebo using the chromatographic conditions defined for the proposed method. It was found that there is no interference due to excipients in the tablet formulation and also found good correlation between the retention times of standard and sample. The chromatograms of standar, sample, blank and placebo for Proguanil and Atovaquone were shown in figure 3, 4, 5 \& 6 .

\section{Linearity}

A Linearity was performed by preparing mixed standard solutions of Proguanil and Atovaquone at different concentration levels including working concentration mentioned in experimental condition i.e., 25-150 $\mu \mathrm{g} / \mathrm{mL}$ for Proguanil and 62.5-375 $\mu \mathrm{g} / \mathrm{mL}$ for Atovaquone respectively. Ten microlitres of each concentration was injected in duplicate into the HPLC system. The response was read at $287 \mathrm{~nm}$ and the corresponding chromatograms were recorded. From these chromatograms, the mean peak areas were calculated and linearity plots of concentration over the mean peak areas were constructed individually. The regressions of the plots were computed by least square regression method. Linearity results were presented in Table 1 and linearity plots are shown in figure $7 \& 8$. 


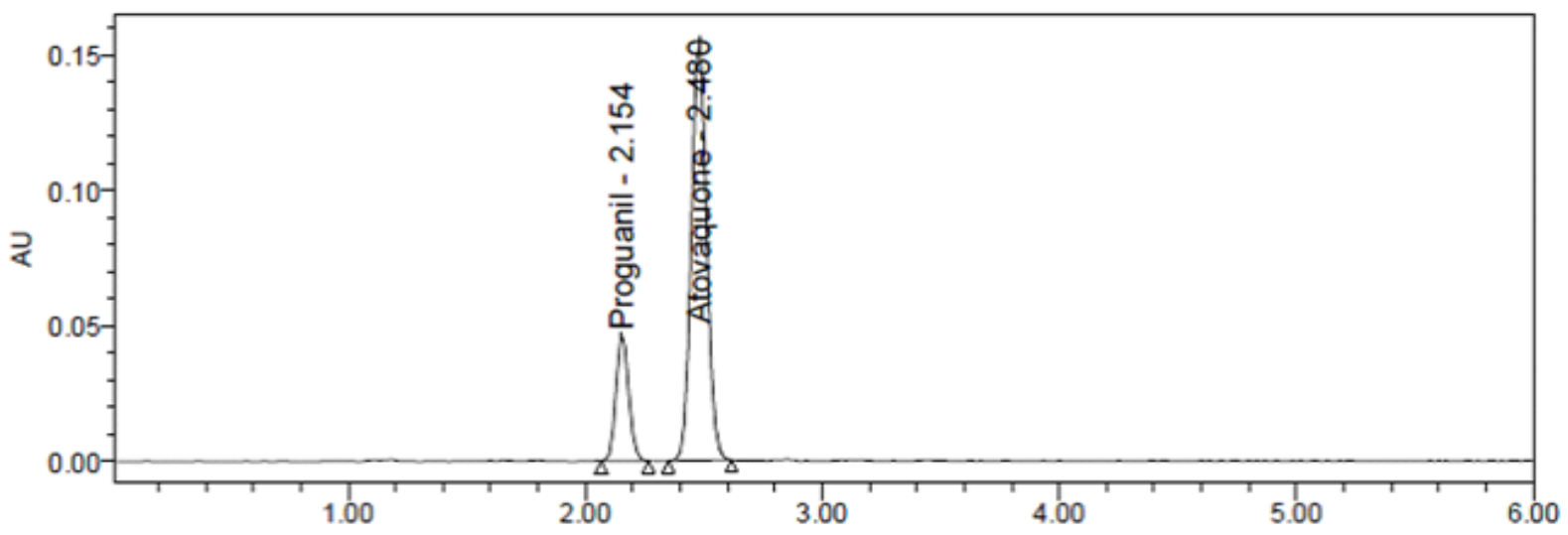

Figure 3: Chromatogram of standard solution of Proguanil and Atovaquone

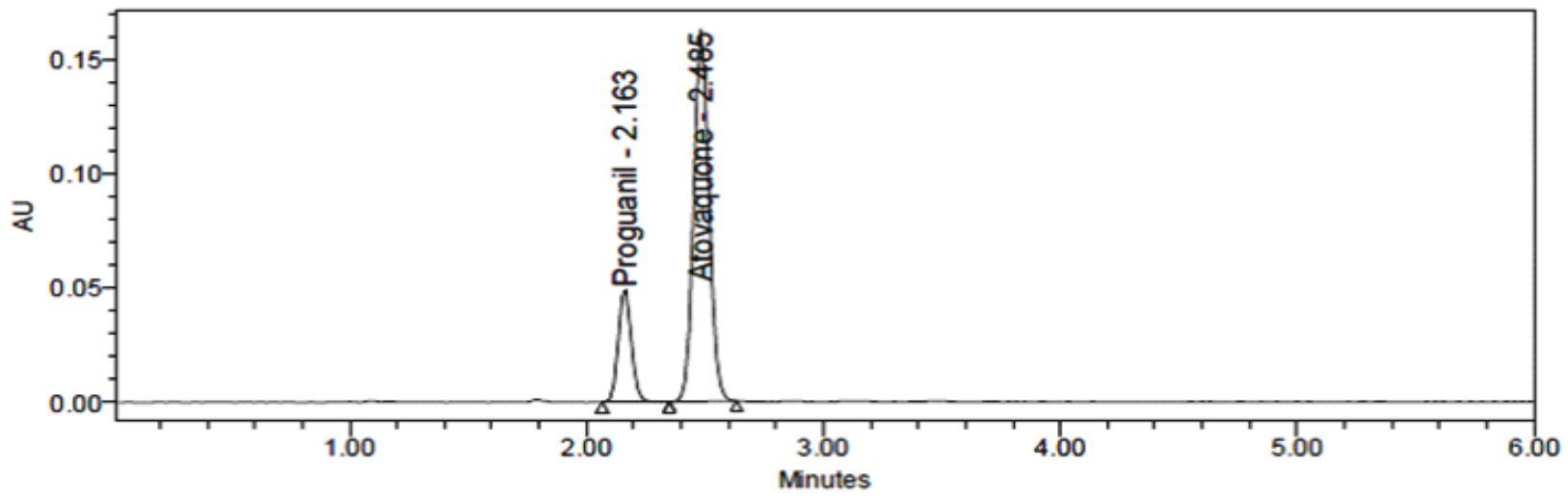

Figure 4: Chromatogram of sample solution of Proguanil and Atovaquone

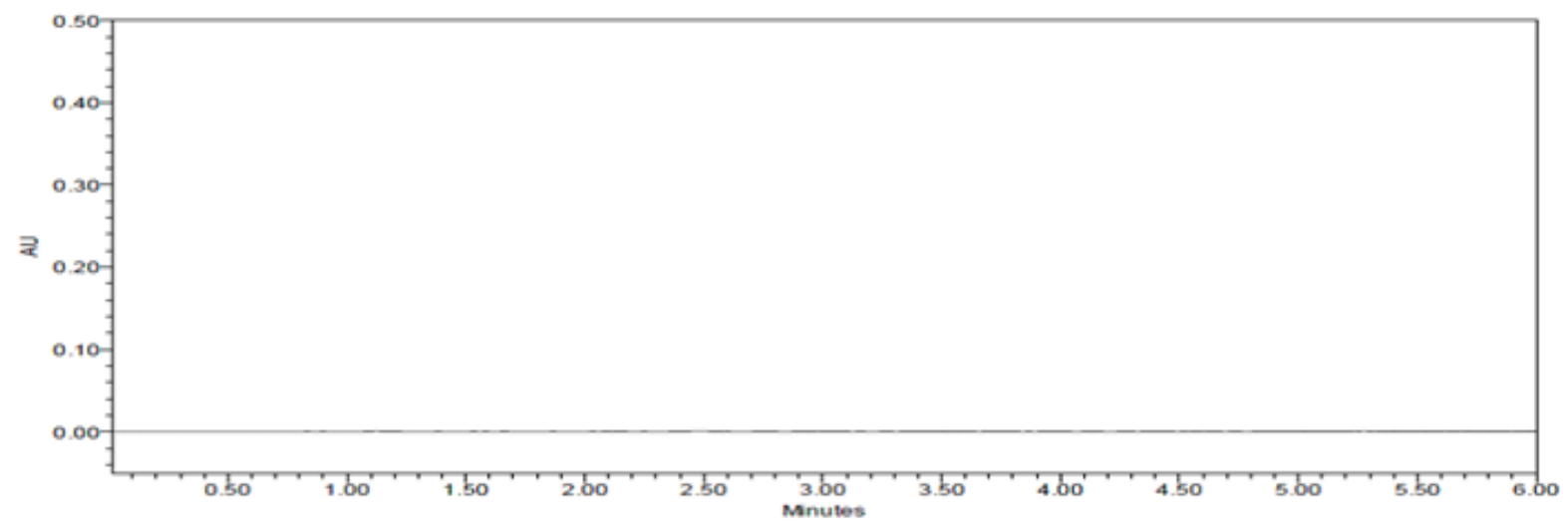

Figure 5:Chromatogram of blank for Proguanil and Atovaquone 


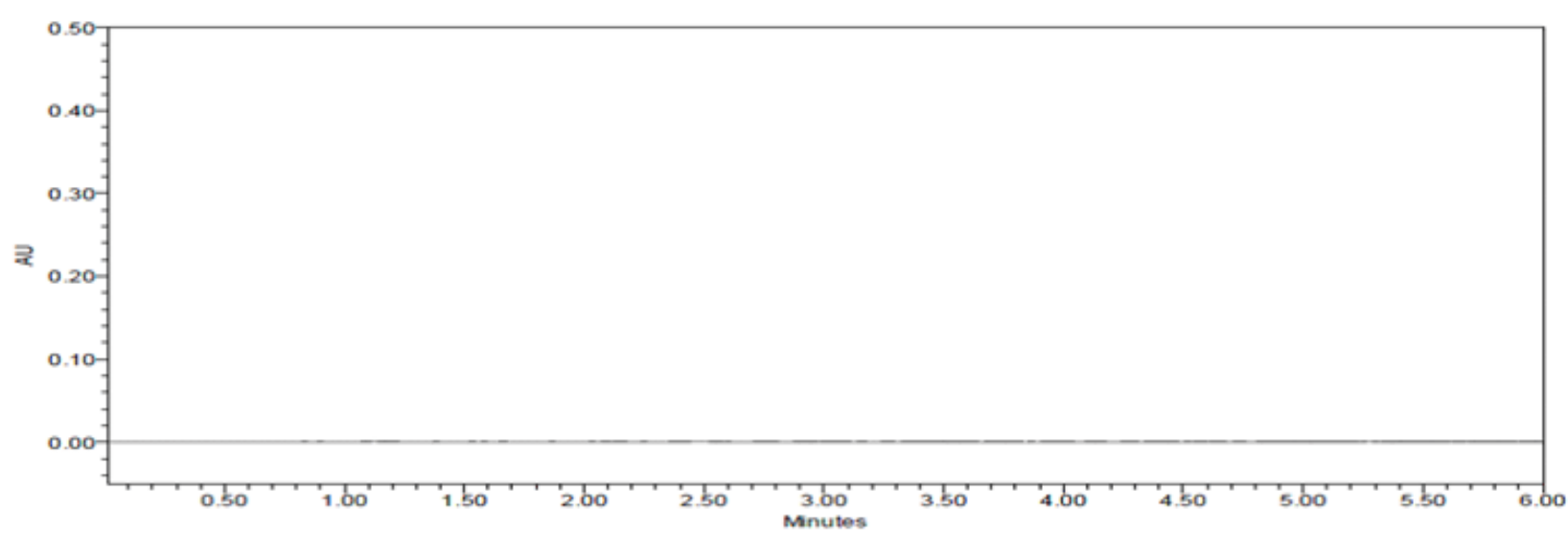

Figure 6:Chromatogram of placebo for Proguanil and Atovaquone

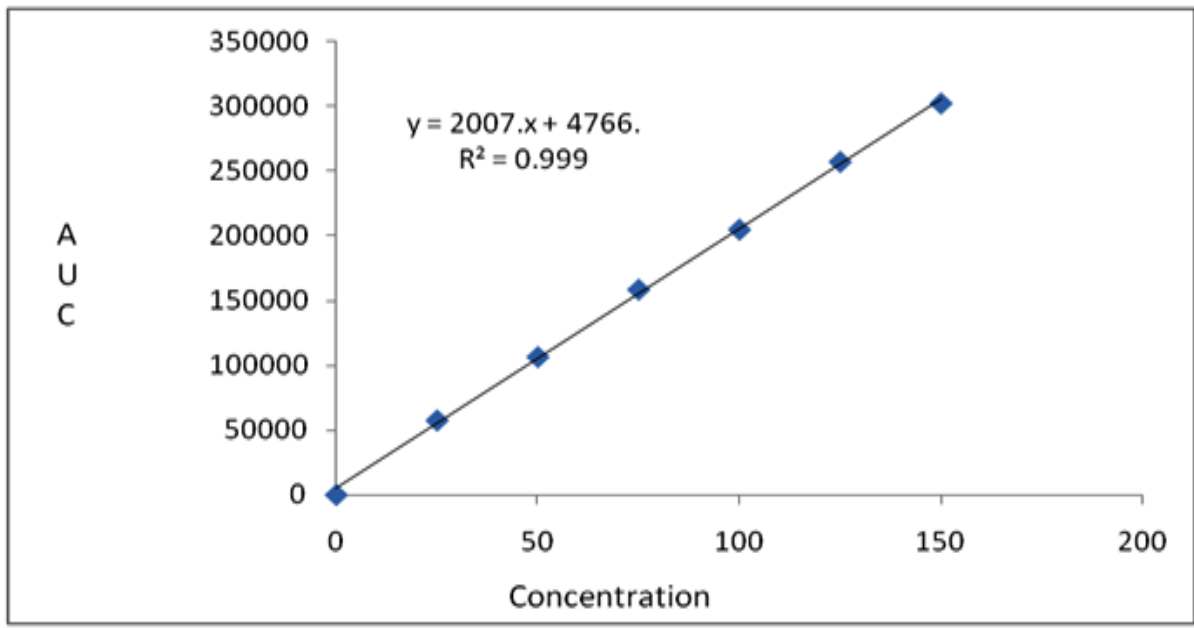

Figure 7:Linearity plot of Proguanil

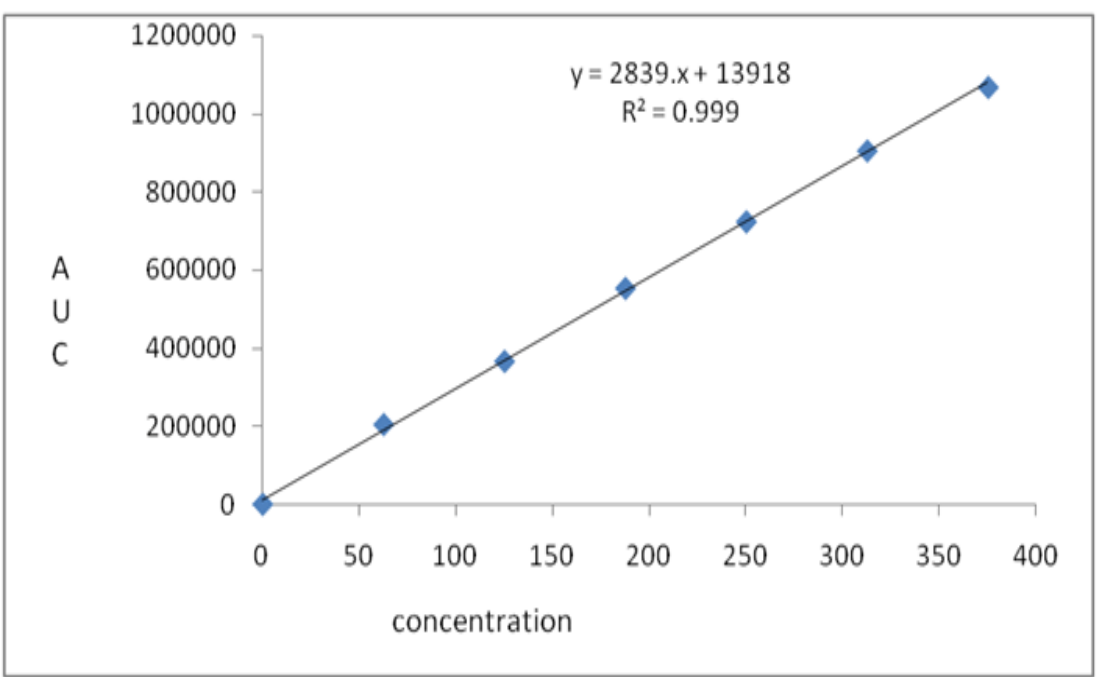

Figure 8:Linearity plot of Atovaquone 
Table 1: Linearity results

\begin{tabular}{|c|c|c|c|c|}
\hline \multirow[b]{2}{*}{ S. No. } & \multirow{2}{*}{$\begin{array}{c}\text { Proguanil } \\
\text { Conc. } \\
(\mu \mathrm{g} / \mathrm{mL})\end{array}$} & \multirow[b]{2}{*}{$\begin{array}{c}\text { Peak } \\
\text { area }\end{array}$} & \multicolumn{2}{|c|}{ Atovaquone } \\
\hline & & & $\begin{array}{c}\text { Conc. } \\
(\mu \mathrm{g} / \mathrm{mL})\end{array}$ & Peak area \\
\hline 1 & 0 & 0 & 0 & 0 \\
\hline 2 & 25 & 57502 & 62.5 & 204362 \\
\hline 3 & 50 & 106532 & 125 & 366432 \\
\hline 4 & 75 & 158571 & 187.5 & 553837 \\
\hline 5 & 100 & 204908 & 250 & 724409 \\
\hline 6 & 125 & 257251 & 312.5 & 906276 \\
\hline 7 & 150 & 302396 & 375 & 1069232 \\
\hline Slope & \multicolumn{2}{|c|}{2007} & \multicolumn{2}{|c|}{2839} \\
\hline Intercept & \multicolumn{2}{|c|}{4766} & \multicolumn{2}{|c|}{13918} \\
\hline $\begin{array}{l}\text { Regression } \\
\text { Equation(y) }\end{array}$ & \multicolumn{2}{|c|}{$y=2007 x+4766$} & \multicolumn{2}{|c|}{$y=2839 x+13918$} \\
\hline $\begin{array}{l}\text { Correlation } \\
\text { Coefficient }\end{array}$ & \multicolumn{2}{|c|}{0.999} & \multicolumn{2}{|c|}{0.999} \\
\hline
\end{tabular}

\section{System suitability}

To study the system suitability, six replicate mixed standard solutions of Proguanil and Atovaquone were injected. The percent relative standard deviation (\% RSD) was calculated and it was found to be 0.9 and 0.2 for Proguanil and Atovaquone respectively, which are well within the acceptable criteria of not more than 2.0. Results of system suitability studies are shown in Table 2 \& 3.

Table 2: System suitability results for Proguanil

\begin{tabular}{|c|c|c|c|c|}
\hline Injection & $\begin{array}{c}\text { Retention time } \\
\text { (min) }\end{array}$ & $\begin{array}{c}\text { Peak } \\
\text { area }\end{array}$ & $\begin{array}{c}\text { Theoretical } \\
\text { plates }\end{array}$ & $\begin{array}{c}\text { Tailing } \\
\text { factor }\end{array}$ \\
\hline 1 & 2.154 & 175248 & 7534 & 1.11 \\
\hline 2 & 2.155 & 174752 & 7306 & 1.12 \\
\hline 3 & 2.162 & 175329 & 7231 & 1.06 \\
\hline 4 & 2.162 & 172151 & 7297 & 1.05 \\
\hline 5 & 2.163 & 176254 & 7359 & 1.06 \\
\hline 6 & 2.164 & 176312 & 7407 & 1.06 \\
\hline Mean & - & 175008 & - & - \\
\hline SD & - & 1526.0 & - & - \\
\hline$\% R S D$ & - & 0.9 & - & - \\
\hline
\end{tabular}

\section{Precision}

\section{Intra-day precision}

The Intra-day precision study was carried out on six preparations from the same tablet samples of Proguanil and Atovaquone and percent amount of both were calculated. The $\%$ RSD of the assay result of six preparations in method precision study was found to be 0.8 and 0.2 for Proguanil and Atovaquone respectively, which are well within the acceptance criteria of not more than 2.0. The results obtained for assay of Proguanil and Atovaquone are presented in Table 4.

\begin{tabular}{|c|c|c|c|c|}
\hline \multicolumn{6}{|c|}{ Table 3: System suitability results for Atovaquone } \\
\hline Injection & $\begin{array}{c}\text { Retention time } \\
\text { (min) }\end{array}$ & $\begin{array}{c}\text { Peak } \\
\text { area }\end{array}$ & $\begin{array}{c}\text { Theoretical } \\
\text { plates }\end{array}$ & $\begin{array}{c}\text { Tailing } \\
\text { factor }\end{array}$ \\
\hline 1 & 2.48 & 692222 & 6904 & 1.04 \\
\hline 2 & 2.482 & 694317 & 7132 & 1.05 \\
\hline 3 & 2.485 & 692948 & 6964 & 1.06 \\
\hline 4 & 2.485 & 692469 & 7122 & 1.07 \\
\hline 5 & 2.485 & 691389 & 7129 & 1.07 \\
\hline 6 & 2.486 & 694015 & 7033 & 1.07 \\
\hline Mean & - & 692893 & - & - \\
\hline SD & - & 1112.0 & - & - \\
\hline \%RSD & - & 0.2 & - & - \\
\hline
\end{tabular}

Table 4: Intra-day precision results

\begin{tabular}{|c|c|c|}
\hline S. No. & Proguanil & Atovaquone \\
\hline 1 & 173280 & 691365 \\
\hline 2 & 172224 & 693400 \\
\hline 3 & 171965 & 693006 \\
\hline 4 & 174501 & 694414 \\
\hline 5 & 175218 & 691224 \\
\hline 6 & 172484 & 690675 \\
\hline Mean & 173279 & 692347 \\
\hline Std. Dev. & 1321 & 1472.2 \\
\hline \%RSD & 0.8 & 0.2 \\
\hline
\end{tabular}

\section{Inter-day precision}

The inter-day precision study was carried out by different analysts, different columns, different reagents using different HPLC systems from the same tablet of Proguanil and Atovaquone and the percent amount for Proguanil and Atovaquone was calculated. The \%RSD of the assay result of six preparations in intermediate precision study was $0.7 \%$ for both Proguanil and Atovaquone respectively, which are well within the acceptance criteria of not more than 2.0. The results of intermediate precision study are reported in Table 5.

\begin{tabular}{|c|c|c|}
\hline \multicolumn{3}{|c|}{ Table 5: Inter-day precision results } \\
\hline S. No. & Proguanil & Atovaquone \\
\hline 1 & 190935 & 752329 \\
\hline 2 & 192023 & 747166 \\
\hline 3 & 192853 & 742244 \\
\hline 4 & 189062 & 753322 \\
\hline 5 & 192173 & 756517 \\
\hline 6 & 190906 & 747570 \\
\hline Mean & 191325 & 749858 \\
\hline Std. Dev. & 1340.9 & 5155.6 \\
\hline \%RSD & 0.7 & 0.7 \\
\hline
\end{tabular}




\section{Accuracy}

The accuracy of the method was determined by standard addition method. A known amount of standard drug was added to the fixed amount of pre-analyzed tablet solution. Percent recovery was calculated by comparing the area before and after the addition of the standard drug. The standard addition method was performed at three concentration levels of $50 \%, 100 \%$ and $150 \%$. The solutions were analyzed in triplicate at each level as per the proposed method. The percent recovery and \%RSD at each level was calculated and results are presented in Table 6. Satisfactory recoveries ranging from 98.86 to 99.77 for Proguanil hydrochloride and 99.52 to 99.71 for Atovaquone respectively were obtained by the proposed method. This indicates that the proposed method was accurate.

\section{Robustness}

The robustness study was performed by slight modification in flow rate of the mobile phase, $\mathrm{pH}$ of the buffer and composition of the mobile phase. It was observed that there were no marked changes in chromatograms, which demonstrated that the developed method was robust in nature. The results are presented in Table 7.

\begin{tabular}{|c|c|c|c|c|c|c|c|}
\hline Sample & Recovery Level & Peak area & $\begin{array}{l}\text { Standard Amount added } \\
(\mu \mathrm{g} / \mathrm{mL})\end{array}$ & $\begin{array}{l}\text { Amount added } \\
(\mu \mathrm{g} / \mathrm{mL})\end{array}$ & $\begin{array}{c}\text { Amount Recovered } \\
(\mu \mathrm{g} / \mathrm{mL})\end{array}$ & $\begin{array}{c}\text { Recovery } \\
\text { (\%) }\end{array}$ & Average \\
\hline \multirow{9}{*}{ Proguanil } & \multirow{3}{*}{$50 \%$} & 305664 & 100 & 50 & 49.92 & 99.85 & \multirow{3}{*}{99.77} \\
\hline & & 304589 & 100 & 50 & 49.39 & 98.78 & \\
\hline & & 306495 & 100 & 50 & 50.34 & 100.68 & \\
\hline & \multirow{3}{*}{$100 \%$} & 404528 & 100 & 100 & 99.18 & 99.18 & \multirow{3}{*}{98.56} \\
\hline & & 404129 & 100 & 100 & 98.985 & 98.99 & \\
\hline & & 402958 & 100 & 100 & 98.4 & 98.4 & \\
\hline & \multirow{3}{*}{$150 \%$} & 502926 & 100 & 150 & 148.21 & 98.81 & \multirow{3}{*}{99.06} \\
\hline & & 503847 & 100 & 150 & 148.67 & 99.11 & \\
\hline & & 504308 & 100 & 150 & 148.9 & 99.27 & \\
\hline \multirow{9}{*}{ Atovaquone } & \multirow{3}{*}{$50 \%$} & 1075503 & 250 & 125 & 123.93 & 99.14 & \multirow{3}{*}{99.79} \\
\hline & & 1076502 & 250 & 125 & 124.3 & 99.42 & \\
\hline & & 1081360 & 250 & 125 & 125.992 & 100.79 & \\
\hline & \multirow{3}{*}{$100 \%$} & 1438311 & 250 & 250 & 251.72 & 100.69 & \multirow{3}{*}{99.52} \\
\hline & & 1421537 & 250 & 250 & 245.82 & 98.33 & \\
\hline & & 1430215 & 250 & 250 & 248.87 & 99.55 & \\
\hline & \multirow{3}{*}{$150 \%$} & 1783229 & 250 & 375 & 373.22 & 99.52 & \multirow{3}{*}{99.71} \\
\hline & & 1778040 & 250 & 375 & 371.39 & 99.04 & \\
\hline & & 1794479 & 250 & 375 & 377.18 & 100.58 & \\
\hline
\end{tabular}

Table 7: Results for Robustness

\begin{tabular}{|c|c|c|c|}
\hline S. No. & $\begin{array}{c}\text { Robustness } \\
\text { condition }\end{array}$ & $\begin{array}{c}\text { Proguanil } \\
\text { \%RSD }\end{array}$ & $\begin{array}{c}\text { Atovaquone } \\
\text { \%RSD }\end{array}$ \\
\hline 1 & Flow minus & 0.5 & 0.3 \\
\hline 2 & Flow plus & 0.8 & 0.5 \\
\hline 3 & Mobile phase minus & 0.9 & 0.8 \\
\hline 4 & Mobile phase plus & 0.5 & 0.3 \\
\hline 5 & Temperature minus & 0.7 & 0.6 \\
\hline 6 & Temperature plus & 1.1 & 0.8 \\
\hline & & & \\
\hline
\end{tabular}

\section{Limit of detection and Limit of quantification}

For this study six replicates of the analyte at lowest concentration were measured and quantified. Limit of detection was calculated by intercept method and LOD for Proguanil was found to be 0.88 and Atovaquone was $1.10 \mu \mathrm{g} / \mathrm{mL}$ respectively. Limit of Quantification was calculated by intercept method and LOQ for Proguanil and Atovaquone were found to be 2.65 and $3.33 \mu \mathrm{g} / \mathrm{mL}$ respectively.

\section{Assay}

Standard preparations are made from the API and sample preparations are from formulation. Both sample and standards are injected six homogeneous samples. The average $\%$ assay was calculated and found to be $98.91 \%$ and $99.82 \%$ for Proguanil and Atovaquone respectively. The results were represented in Table 8. 


\begin{tabular}{|c|c|c|}
\hline \multicolumn{3}{|c|}{ Table 8: Assay data of Proguanil and Atovaquone } \\
\hline S. No. & Proguanil & Atovaquone \\
\hline & \%Assay & \%Assay \\
\hline 1 & 98.91 & 99.68 \\
\hline 2 & 98.31 & 99.97 \\
\hline 3 & 98.16 & 99.92 \\
\hline 4 & 99.61 & 100.12 \\
\hline 5 & 100.02 & 99.66 \\
\hline 6 & 98.46 & 99.58 \\
\hline Avg & 98.91 & 99.82 \\
\hline Std.Dev. & 0.75 & 0.21 \\
\hline \%RSD & 0.76 & 0.21 \\
\hline
\end{tabular}

\section{Stability studies}

In order to demonstrate the stability of both standard and sample solutions during analysis, both solutions were analyzed over a period of 24 hours at room temperature. The results shown that for both solutions, the retention time and peak area of Proguanil and Atovaquone remained almost similar (\%RSD less than 2.0) and no significant degradation within the indicated period, thus indicated that both solutions were stable for at least 24 hours, which was sufficient to complete the whole analytical process. Further forced degradation studies were conducted indicating the stability of proposed method. The results of the degradation studies are shown in the Table 9.

Table 9: Degradation Studies

\begin{tabular}{|c|c|c|c|c|c|c|}
\hline \multirow{2}{*}{ Type of degradation } & \multicolumn{3}{|c|}{ Proguanil } & \multicolumn{3}{c|}{ Atovaquone } \\
\cline { 2 - 7 } & Area \% & Recovered \% & Degraded \% & Area \% & Recovered \% & Degraded \% \\
\hline Acid & 166958 & 95.3 & 4.7 & 660534 & 95.23 & 4.77 \\
\hline Base & 169958 & 97.02 & 2.98 & 673534 & 97.11 & 2.89 \\
\hline Peroxide & 171993 & 98.18 & 1.82 & 679716 & 98.00 & 2.00 \\
\hline Thermal & 173446 & 99.01 & 0.99 & 688538 & 99.27 & 0.73 \\
\hline UV & 174006 & 99.33 & 0.67 & 689734 & 99.44 & 0.56 \\
\hline Neutral & 174142 & 99.31 & 0.69 & 68922 & 99.37 & 0.63 \\
\hline
\end{tabular}

\section{Control sample}

Twenty tablets were weighed and finely powdered. An accurately weighed portion of powder sample equivalent to 10 $\mathrm{mg}$ of Proguanil and $25 \mathrm{mg}$ of Atovaquone was transferred to a $10 \mathrm{~mL}$ volumetric flask containing diluent. The contents of the flask were sonicated for about 30 min for complete solubility of the drug with intermittent shaking at controlled temperature and then cooled the solution to room temperature and volume made up with further quantity of diluent. Then this mixture was filtered through $0.45 \mu$ membrane filter. Pipetted $1 \mathrm{~mL}$ of the above filtered sample solution into a $10 \mathrm{~mL}$ volumetric flask and diluted to volume with diluent.

\section{Acid degradation sample}

Twenty tablets were weighed and finely powdered. An accurately weighed portion of powder sample equivalent to $10 \mathrm{mg}$ of Proguanil hydrochloride and $25 \mathrm{mg}$ of Atovaquone was transferred to a $10 \mathrm{~mL}$ volumetric flask containing diluent. The contents of the flask were sonicated for about $30 \mathrm{~min}$ for complete solubility of the drug with intermittent shaking at controlled temperature. Then $2 \mathrm{~mL}$ of $5 \mathrm{~N}$ acid (Hydrochloric acid) was added, refluxed for 60 minutes at $60^{\circ} \mathrm{C}$, then cooled to room temperature, neutralized with $5 \mathrm{~N}$ base (Sodium hydroxide) and diluted to volume with diluent. Then this mixture was filtered through $0.45 \mu$ membrane filter. Pipetted $1 \mathrm{~mL}$ of the above filtered sample solution into a $10 \mathrm{~mL}$ volumetric flask and diluted to volume with diluent. Typical chromatogram of acid degradation for Proguanil and Atovaquone is shown in figure 9.

\section{Base degradation sample}

Twenty tablets were weighed and finely powdered. An accurately weighed portion of powder sample equivalent to 10 $\mathrm{mg}$ of Proguanil hydrochloride and $25 \mathrm{mg}$ of Atovaquone was transferred to a $10 \mathrm{~mL}$ volumetric flask containing diluent. The contents of the flask were sonicated for about $30 \mathrm{~min}$ for complete solubility of the drug with intermittent shaking at controlled temperature. Then $2 \mathrm{~mL}$ of $5 \mathrm{~N}$ base (Sodium hydroxide) was added, refluxed for 60 minutes at $60^{\circ} \mathrm{C}$, then cooled to room temperature, neutralized with $5 \mathrm{~N}$ acid (Hydrochloric acid) and diluted to volume with diluent. Then this mixture was filtered through $0.45 \mu$ membrane filter. Pipetted $1 \mathrm{~mL}$ of the above filtered sample solution into a $10 \mathrm{~mL}$ volumetric flask and diluted to volume with diluent. Typical chromatogram of base degradation for Proguanil and Atovaquone is shown in figure 10.

\section{Peroxide degradation sample}

Twenty tablets were weighed and finely powdered. An accurately weighed portion of powder sample equivalent to 10 $\mathrm{mg}$ of Proguanil and $25 \mathrm{mg}$ of Atovaquone was transferred to a $10 \mathrm{~mL}$ volumetric flask containing diluent. The contents of the flask were sonicated for about $30 \mathrm{~min}$ for complete solubility of the drug with intermittent shaking at controlled temperature. Then $0.5 \mathrm{~mL}$ of $30 \%$ peroxide was added, refluxed for 60 minutes at $60^{\circ} \mathrm{C}$, then cooled to room temperature and diluted to volume with diluent. Then this mixture was filtered through $0.45 \mu$ membrane filter. Pipetted $1 \mathrm{~mL}$ of the above filtered sample solution into a $10 \mathrm{~mL}$ volumetric flask and diluted to volume with diluent. Typical chromatogram of peroxide degradation for Proguanil and Atovaquone is shown in figure 11. 




Figure 9:Chromatogram of acid degradation showing Proguanil and Atovaquone

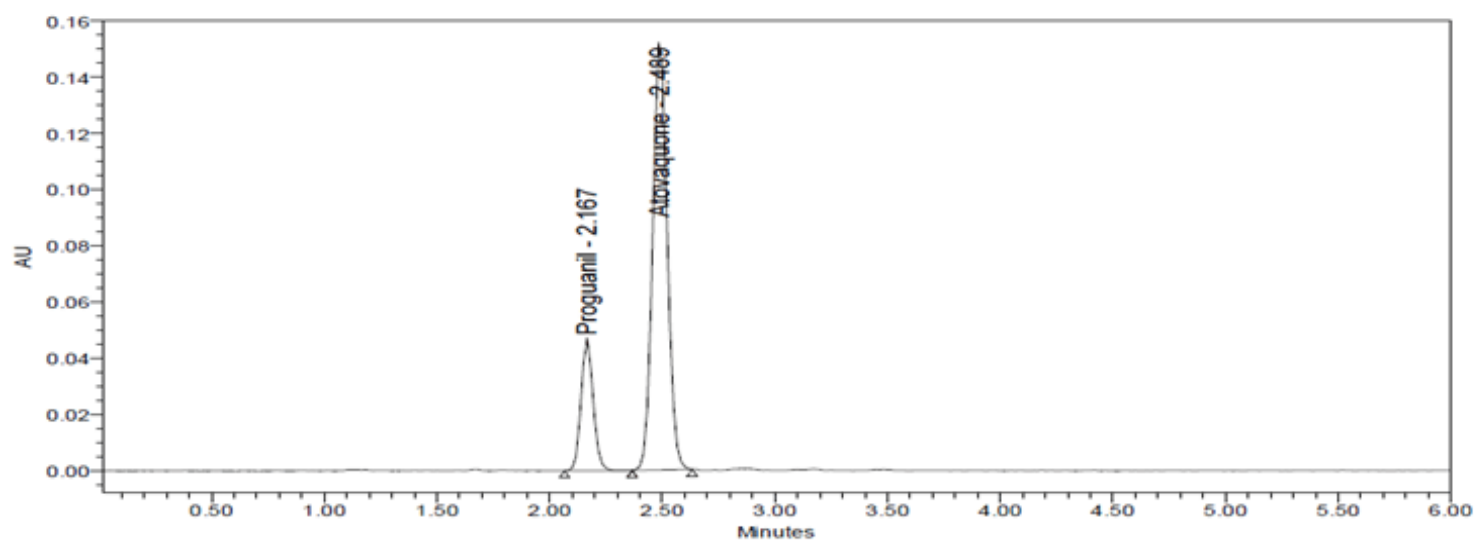

Figure 10:Chromatogram of base degradation showing Proguanil and Atovaquone

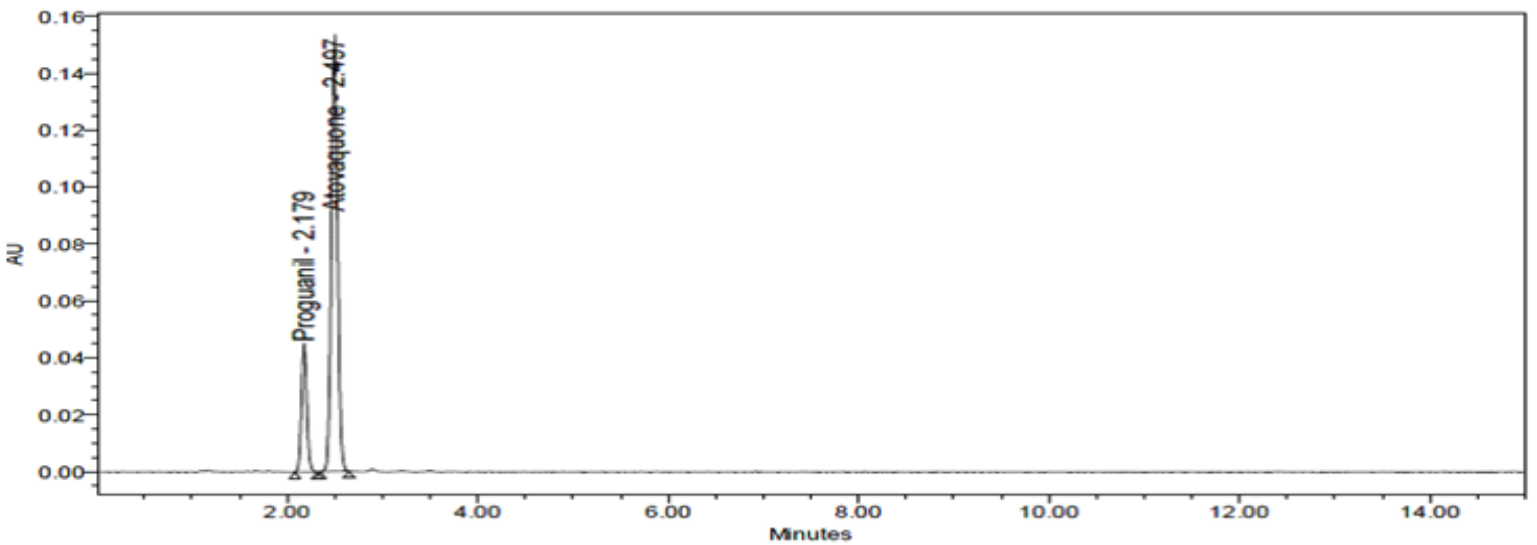

Figure 11:Chromatogram of oxidative degradation showing Proguanil and Atovaquone

\section{Thermal degradation sample}

Twenty tablets were weighed and finely powdered. The powder is exposed to heat at $105^{\circ} \mathrm{C}$ for about 2 days. An accurately weighed portion of powder sample equivalent to 10 mg of Proguanil hydrochloride and $25 \mathrm{mg}$ of Atovaquone was transferred to a $10 \mathrm{~mL}$ volumetric flask containing diluent. The contents of the flask were sonicated for about $30 \mathrm{~min}$ for complete solubility of the drug with intermittent shaking at controlled temperature and then cooled the solution to room temperature and volume made up with further quantity of diluent. Then this mixture was filtered through $0.45 \mu$ membrane filter. Pipetted 1 $\mathrm{mL}$ of the above filtered sample solution into a $10 \mathrm{~mL}$ volumetric flask and diluted to volume with diluent. Typical chromatogram of thermal degradation for Proguanil hydrochloride and Atovaquone is shown in figure 12 . 


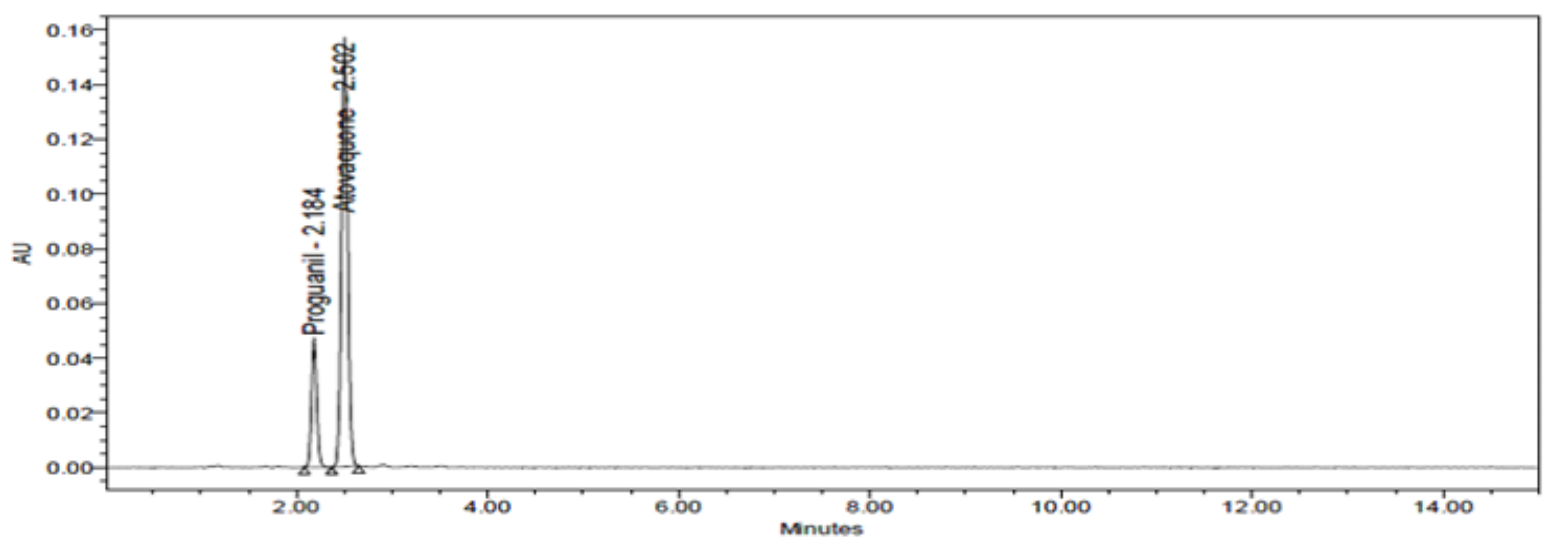

Figure 12:Chromatogram of thermal degradation showing Proguanil and Atovaquone

\section{Photo stability studies}

Twenty tablets were weighed and finely powdered. An accurately weighed portion of powder sample equivalent to 10 $\mathrm{mg}$ of Proguanil hydrochloride and $25 \mathrm{mg}$ of Atovaquone was transferred to a $10 \mathrm{~mL}$ volumetric flask containing diluent. The contents of the flask were sonicated for about $30 \mathrm{~min}$ for complete solubility of the drug with intermittent shaking at controlled temperature and then cooled the solution to room temperature and volume made up with further quantity of diluent. Then this mixture was filtered through $0.45 \mu$ membrane filter. Pipetted 1 $\mathrm{mL}$ of the above filtered sample solution into a $10 \mathrm{~mL}$ volumetric flask and diluted to volume with diluent. The photochemical stability of the drug was also studied by exposing the above solution to UV light by keeping the beaker in UV Chamber for 7 days or 200 Watt hours $/ \mathrm{m}^{2}$ in photo stability chamber. Typical chromatogram of photo stability for Proguanil hydrochloride and Atovaquone is shown in figure 13.

\section{Neutral degradation studies}

Stress testing under neutral conditions was studied by refluxing the drug in water for $6 \mathrm{hrs}$ at a temperature of $60^{\circ} \mathrm{C}$. Typical chromatogram of neutral degradation for Proguanil hydrochloride and Atovaquone is shown in figure 14.

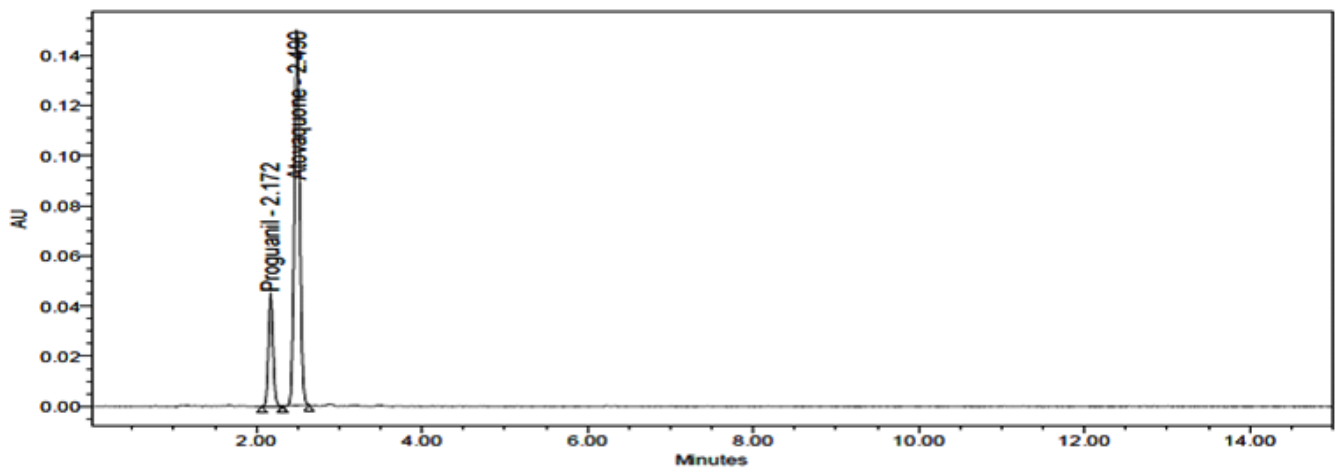

Figure 13:Chromatogram of Photo stability showing Proguanil and Atovaquone

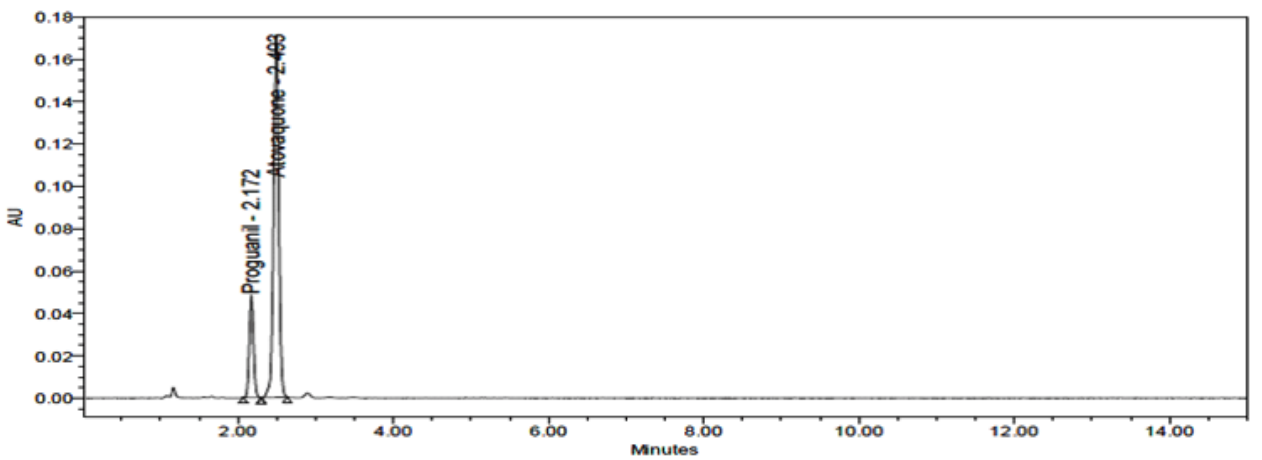

Figure 14:Chromatogram of Neutral degradation showing Proguanil and Atovaquone 


\section{Results and Discussion}

The present study was aimed at developing a simple, sensitive, precise and accurate RP-HPLC method for the simultaneous estimation of Proguanil and Atovaquone from bulk samples and their tablet dosage forms. Kromasil C18(150 mm X $4.6 \mathrm{~mm}, 5 \mu)$ analytical chromatographic column was chosen as the stationary phase for the separation and simultaneous determination of Proguanil and Atovaquone. Mixtures of commonly used solvents like water, methanol and acetonitrile with or without buffers in different combinations were tested as mobile phases. The choice of the optimum composition is based on the chromatographic response factor, a good peak shape with minimum tailing. A mixture of $0.1 \% \mathrm{OPA}$ and acetonitrile in the ratio of 50:50 v/v was proved to be the most suitable of all the combinations since the chromatographic peak obtained was well defined, better resolved and almost free from tailing. The retention times of the Proguanil and Atovaquone were found to be 2.155 and $2.482 \mathrm{~min}$ respectively. The linearity was found satisfactory for both the drugs in the range of 62.5 to $375 \mu \mathrm{g} / \mathrm{mL}$ for Proguanil and 25 to $150 \mu \mathrm{g} / \mathrm{mL}$ for Atovaquone respectively. The regression equation of the linearity curve between concentrations of Proguanil and Atovaquone over its peak areas were found to be $\mathrm{y}=2007 \mathrm{x}+$ 4766 and $y=2839 x+13918$ respectively. Precision of the method was studied by repeated injection of tablet solution and results showed lower \%RSD values. This reveals that the method is quite precise. The percent recoveries of the drug solutions were studied at three different concentration levels. The percent individual recovery and the \%RSD at each level were within the acceptable limits. This indicates that the method is accurate. The absence of additional peaks in the chromatogram indicates non-interference of the commonly used excipients in the tablets and hence the method is specific. The deliberate changes in the method have not much affected the peak tailing, theoretical plates and the percent assay. This indicates that the present method is robust. The system suitability studies were carried out to check various parameters such as theoretical plates and tailing factor. The lowest values of LOD and LOQ as obtained by the proposed method indicate that the method is sensitive. The solution stability studies indicate that both the drugs were stable up to 24 hours. The forced degradation studies indicate that both the drugs Proguanil and Atovaquone were stable in stability studies.

\section{Conclusion}

The present study demonstrated a validated Reverse Phase High Performance Liquid Chromatography method for the estimation of Proguanil and Atovaquone available as tablet dosage form. Literature review revealed that only few instrumental methods have been reported to determine Proguanil and Atovaquone individually in formulation. The scope of the present work is to build up the linear and optimized of the chromatographic conditions and RP-HPLC method for the estimation of drug in tablet dosage form. The method was completely validated and showed satisfactory results. The method was free from interference of the other active ingredients and additives used in the formulation. Retention time and runtime was decreased, So the developed method can be used for simultaneous analysis of Proguanil and Atovaquone in pharmaceutical dosage forms.

\section{References}

1. Nixon GL, Moss DM, Shone AE, Ward SA, Biagini GA, Lalloo DG, et al. Antimalarial pharmacology and therapeutics of Atovaquone. J of Antimicrob Chemother. 2013;68(5):977-985. DOI: 10.1093/jac/ dks504

2. Ryley JF. The mode of action of Proguanil and related antimalarial drugs. Br J Pharmacol. 1953;8(4):424-430.

3. Patel RKN, Patel JK, Patel MP, Rajput GC. A validated method for development of Proguanil as API and tablet dosage forms by UV spectroscopy. Pharm Methods. 2010;1(1):61-64. DOI:10.4103/22294708.72234

4. Nandini RP, Seema SS. Development and validation of stability indicating RP-HPLC method for estimation of Proguanil Hydrochloride in tablet dosage form. J Chem Pharma Sci. 2013;3(4);206-217.

5. Viplava K, Pavani HV. Development and validation of stability-indicating RP-HPLC method for estimation of Atovaquone hydrochloride in tablet dosage form. Int J Pharma Cli Res. 2012;4(4):68-72.

6. Gurule S, Goswami D, Khuroo AH, Monif T. LC-APCI mass spectrometric method development and validation for the determination of Atovaquone in human plasma. Biomed Chromat. 2010;24(5):497-505. DOI:10.1002/bmc.1317

7. Patil SD, Kokatea SD, Mohitea SK, Magduma CS. Development and validation of RP-HPLC method on Atovaquone in bulk and tablet dosage form. Cur Pharma Res. 2013;4(1):1093-1096.

8. Pingale SG, Nerurkar KK, Padgaonkar AM, Pawar UD, Mangaonkar KV. Alternative LC-MS-MS method for simultaneous determination of Atovaquone, its active metabolite in human plasma and application to a bioequivalence study. Chromatographia. 2009;70(7-8):1095-1102. DOI:10.1365/s10337-009-1259-9

9. Sumanth K, Kumari KJL, Sreelekha P, Chandana A, Suresh ChV. Development and validation of simple spectrophotometric, first and second derivative spectroscopy for estimation of Atovaquone in bulk and pharmaceutical formulations. J Res Pharma Prac. 2011;2(2):261265.

10. Jadhav NS, Lalitha J. Spectroscopic method development and validation for simultaneous estimation of Atovaquone and Proguanil in tablet dosage form. W J Pharm Pharma Sci. 2014;3(6):1986-1994.

11.Veer VS, Badgujar MA, Kiran VM. Simultaneous determination of Proguanil and Atovaquone hydrochloride in tablet dosage form by high performance liquid chromatography. Res J Pharma. Biol Chem Sci. 2012;3(4):377.

12. Sahoo S, Panda PK, Mishra SK. HPLC method development for simultaneous estimation of Proguanil and Atovaquone in tablet dosage form. Int J Pharm Pharma Sci. 2012;4(3):212.

13. Veer VS, Pingale SG, Manfaonkar KV. Ultra Performance Liquid Chromatography method for simultaneous determination of Atovaquone and Proguanil in rabbit plasma and its application to a pharmacokinetic study. J Liq Chroma Tech. 2013;37(14):1953-1967. DOI: org/10.1080/10826076.2013.825854

14.ICH Harmonised Tripartite Guideline. Validation of Analytical Procedures: Text and Methodology, Q2(R1), USA, 2005; 1-13.

15. ICH Harmonised Tripartite Guideline. Stability Testing of New Drug Substances and Products, Q1A(R2), USA, 2003; 1-18. 